\title{
Stress urinary incontinence after labor and satisfaction with sex life
}

\author{
Grazyna Stadnicka ${ }^{1}$, Anna Stodolak² , Anna B. Pilewska-Kozak ${ }^{3}$ \\ ${ }^{1}$ Department of the Basics of Midwifery, Faculty of Health Sciences, Medical University of Lublin, Poland \\ ${ }^{2}$ Poland Department of Paediatrics, Division of Propaedeutics of Paediatrics Rare Disorders, Wroclaw Medical University, Poland \\ ${ }^{3}$ Chair and Department of Gynecology and Gynecological Endocrinology, Faculty of Health Sciences Medical University, Lublin, Poland
}

\begin{abstract}
Objectives: The aim of the study was to assess the incidence of stress urinary incontinence in women after labor, its determinants, and to establish its effect on women's satisfaction with their sex lives.

Material and methods: The research implemented the Gaudenz-Incontinence-Questionnaire and the Sexual Quality of Life-Female scale (SQLL-F). The principal inclusion criterion was the time of 3 to 6 months after labor.

Results: The research was carried out amongst 193 women. Thirty-two of the participants (16.6\%) showed symptoms of stress urinary incontinence after labor that were statistically correlated with the number of experienced labors $(p=0.044)$ and the newborn's weight $(p=0.016)$. The participants' sex life satisfaction was on average $75.47 \pm 24.68$. The respondents suffering from stress urinary incontinence obtained a significantly lower $(p=0.006)$ average score for general sex life satisfaction (64.38 \pm 26.15$)$ when compared with women without symptoms of stress urinary incontinence $(77.67 \pm 23.86)$.

Conclusions: The problem of incontinence after labor affected one in six women. Occupation, number of pregnancies, damage to the perineum during labor, and the infant's birth weight significantly dependent on the incontinence occurrence after labor. The onset of incontinence symptoms in women in the reproductive age has an adverse effect on their sex life satisfaction.
\end{abstract}

Key words: parturition; stress urinary incontinence; sexuality

Ginekologia Polska 2019; 90, 9: 500-506

\section{INTRODUCTION}

Urinary incontinence is an important, but often neglected, health problem in women. It is commonly believed that this disorder concerns mostly older people and is a consequence of aging. That is not entirely true because stress urinary incontinence occurs in young, even very young, women [1].

Papers dealing with incontinence after labor focus mostly on the epidemiology of this problem [2] and risk factors [3-5]. Much more rarely do they concern its prevention $[6,7]$ or the effect on sex life [8].

Many women experience a variety of problems associated with their sex life within a short period of time after giving birth. Sexual disorders are inadequately investigated, although they concern 26 to $47 \%$ of women suffering from incontinence. The etiology of the dysfunction is complex, divided into organic and psychological factors $[9,10]$.
The aim of the study was to assess the frequency of stress urinary incontinence in women after labor, its determinants, and to establish its effect on women's sex life satisfaction.

\section{MATERIAL AND METHODS}

The study included 193 women who checked in a women's clinical unit in one of three randomly chosen outpatient departments in Lublin. The inclusion criteria were: obtaining an informed consent to participate in the research and the time between 3 to 6 months after the last labor. The exclusion criteria were based on the information concerning patient's medical history and/or medical documentation that included:

- neurological diseases, mental disorders, congenital malformations in the urinary-reproductive system or fistulas;

- overactive bladder and mixed incontinence; 
- diagnosed inflammation of the urinary tract and/or reproductive organ.

An approval of the Ethics Committee of the Medical University of Lublin (KE-0254/194/2013) was obtained. To ensure ethical clarity, all women who participated in the study were fully informed about the nature and purpose of the study, and the voluntary nature of their participation was emphasized.

To carry out the research, a specially constructed three-part questionnaire was used. Personal information was gathered, consisting of questions regarding socio-demographic data (i.e. age, marital status, place of habitation, education, occupational activity before pregnancy), the number of experienced labors, the method of delivery of the last pregnancy, damage to the perineum during labor, the infant's birth mass, participation in antenatal classes, the existing chronic diseases, the problem of incontinence after labor, Kegel's exercises, and the women's height and weight before pregnancy.

The Gaudenz-Incontinence questionnaire, which is mainly used in Poland to identify the patients with the urinary incontinence, constituted the second part of the inventory. To meet the aims of the study, the following questions were particularly useful:

- Does the involuntary release of urine occur?

- How often does this happen (rarely, occasionally, every day, many times, practically all the time)?

- How much urine is involuntary released (few drops, small portions, heavy leakage)?

- Do you feel that the bladder is empty after urinating (yes, no, not always, I don't know)?

- The involuntary urine release is: not a problem, it can be disturbing, it disturbs a lot, it makes life difficult?

- In which situations does the involuntary urine release happen (when coughing, sneezing, laughing, going upstairs and downstairs, jumping, bouncing, exercising, standing, sitting or lying down)?

The third part included the Sexual Quality of Life-Female (SQoL-F) questionnaire used to assess women's sex life satisfaction within the last 4 weeks. The Polish version of the document was obtained from Mapi Research Trust. The SQoL-F scale consisted of 18 questions, each of them with 6 possible answer variants - I totally agree, I rather agree, I agree to a small degree, I rather disagree, and I totally disagree. Obtaining 0 points meant lack of satisfaction with one's sex life, while 100 points accounted for a high degree of satisfaction.

Information about weight and height was used to calculate Body Mass Index (BMI). World Health Organization (WHO) (WHO Expert Consultation, 2004) criteria were used to categorize participants as: underweight $(\mathrm{BMI}<20)$, normal weight (BMI 20-25), and overweight (BMI $\geq 25.1$ ).
The value of measurable analyzed parameters has been presented using median and standard deviation. To find differences between the groups, the $x^{2}$ and Student's $t$ tests were used. The Shapiro-Wilk test was applied to assess normality of distribution of variables within the studied groups. To examine differences between two groups, the nonparametric Mann-Whitney $U$ test was used, and for more than two groups the Kruskal-Wallis test was applied. In this study, the level of statistical significance was set at $p<0.05$. Database and statistical calculations were performed using Statistica 9.1 software (StatSoft, Poland).

\section{RESULTS}

The age of the study participants ranged between 17 and 41 , mean $28.3 \pm 4.9$ years. The majority of respondents were aged $26-30$ years $(75 ; 38.9 \%)$. Women up to 25 years of age $(62 ; 32.1 \%)$ and 31 years - old or more $(56 ; 29.0 \%)$ constituted the second largest age group. Married women were the majority $(153 ; 79.3 \%)$, while the rest $(40 ; 20.7 \%)$ were single women and divorcees living in informal relationships with a child's father. An overwhelming majority of participants lived in the city $(158 ; 81.9 \%)$ and the rest of them resided in the countryside $(35 ; 18.1 \%)$. Moreover, 140 women had an MA or BA (72.5\%). The remaining $53(27.5 \%)$ had secondary education or lower. It was established that 148 women had worked before pregnancy (76.7\%), out of which 129 (66.8\%) performed intellectual work and 19 (9.9\%) physical work. The study also included 45 unemployed (23.3\%) women.

Additionally, 136 of the studied women had a normal body weight before pregnancy (70.5\%), 40 were overweight $(20.7 \%)$ and 17 were underweight (8.8\%). A majority of respondents gave birth to their first child $(137 ; 71.0 \%)$, the remaining $56(29.0 \%)$ to the subsequent children, i.e. the second $(49 ; 25.4 \%)$ or the third $(7 ; 3.6 \%)$. Moreover, 122 of the women (63.2\%) had a vaginal delivery, while 71 (36.8\%) had a caesarean section. Damage to the perineum (episiotomy, rupture, or both episiotomy and rupture) during labor occurred in 86 women (44.6\%), and did not occur in 107 women (55.4\%). Next, 98 of the examined women (50.8\%) had participated in antenatal classes, while 95 had not (49.2\%). The incidence of chronic diseases (such as: diabetes, hypertension, bronchial asthma, or hypothyroidism) was confirmed by $31(16.1 \%)$ of the examined women, while the remaining 162 (83.9\%) stated having no chronic diseases. Thirty-two of the surveyed women (16.6\%) reported problems with incontinence after labor. The remaining 161 (83.4\%) declared no such problems. Sixty-one (31.6\%) women claimed that they performed Kegel's exercises every day, 73 women (37.8\%) only sometimes, while 59 - not at all (30.6\%).

The dependence between the occurrence of incontinence and education level, occupation, evaluation of body 
Table 1. Urinary incontinence after labor and the study characteristics

\begin{tabular}{|c|c|c|c|c|c|c|}
\hline \multirow{2}{*}{\multicolumn{3}{|c|}{ Study characteristics }} & \multicolumn{2}{|l|}{ Incontinence } & \multicolumn{2}{|c|}{ Statistical analysis } \\
\hline & & & \multirow{2}{*}{$\begin{array}{l}\text { No } \\
n=161 ; 83.4 \% \\
42\end{array}$} & \multirow{2}{*}{$\begin{array}{l}\text { Yes } \\
\mathrm{n}=32 ; 16.6 \% \\
11\end{array}$} & $x^{2}$ & p-value \\
\hline \multirow{4}{*}{ Education } & \multirow{2}{*}{$\begin{array}{l}\text { Secondary education or lower } \\
n=53 ; 27.5 \%\end{array}$} & $\mathrm{n}$ & & & \multirow{4}{*}{0.92} & \multirow{4}{*}{0.337} \\
\hline & & $\%$ & 79.3 & 20.7 & & \\
\hline & \multirow{2}{*}{$\begin{array}{l}\text { College/ University } \\
n=140 ; 72.5 \%\end{array}$} & $n$ & 119 & 21 & & \\
\hline & & $\%$ & 85.0 & 15.0 & & \\
\hline \multirow{6}{*}{ Occupation } & \multirow{2}{*}{$\begin{array}{l}\text { Intellectual work } \\
n=129 ; 66.8 \%\end{array}$} & $\mathrm{n}$ & 108 & 21 & \multirow{6}{*}{7.35} & \multirow{6}{*}{0.023} \\
\hline & & $\%$ & 83.6 & 16.4 & & \\
\hline & \multirow{2}{*}{$\begin{array}{l}\text { Physical work } \\
n=19 ; 9.9 \%\end{array}$} & $\mathrm{n}$ & 12 & 7 & & \\
\hline & & $\%$ & 63.2 & 36.8 & & \\
\hline & \multirow{2}{*}{$\begin{array}{l}\text { Unemployed } \\
n=45 ; 23.3 \%\end{array}$} & $\mathrm{n}$ & 41 & 4 & & \\
\hline & & $\%$ & 91.1 & 8.9 & & \\
\hline \multirow{6}{*}{ Body weight } & \multirow{2}{*}{$\begin{array}{l}\text { Underweight } \\
\mathrm{n}=17 ; 8.8 \%\end{array}$} & $\mathrm{n}$ & 16 & 1 & \multirow{6}{*}{5.20} & \multirow{6}{*}{0.074} \\
\hline & & $\%$ & 94.1 & 5.9 & & \\
\hline & \multirow{2}{*}{$\begin{array}{l}\text { Normal weight } \\
n=136 ; 70.5 \%\end{array}$} & $\mathrm{n}$ & 116 & 20 & & \\
\hline & & $\%$ & 85.3 & 14.7 & & \\
\hline & \multirow{2}{*}{$\begin{array}{l}\text { Overweight } \\
n=40 ; 20.7 \%\end{array}$} & $\mathrm{n}$ & 29 & 11 & & \\
\hline & & $\%$ & 72.5 & 27.5 & & \\
\hline \multirow{4}{*}{ Chronic diseases } & \multirow{2}{*}{$\begin{array}{l}\text { Yes } \\
n=31 ; 16.1 \%\end{array}$} & $n$ & 26 & 5 & \multirow{4}{*}{0.04} & \multirow{4}{*}{0.849} \\
\hline & & $\%$ & 83.9 & 16.1 & & \\
\hline & \multirow{2}{*}{$\begin{array}{l}\text { No } \\
n=162 ; 83.9 \%\end{array}$} & $\mathrm{n}$ & 135 & 27 & & \\
\hline & & $\%$ & 83.3 & 16.7 & & \\
\hline
\end{tabular}

mass, and the presence of chronic diseases are presented in Table 1, whereas the dependence between the number of experienced labors, method of delivery, damage to the perineum during labor and exercising pelvic floor muscles are shown in Table 2.

The occurrence of urinary incontinence after labor was significantly influenced by the type of occupation ( $p=0.023)$. Women with a BMI above 25 (overweight/obese) declared incontinence symptoms more often than women of the normal body weight or those underweight. No statistically significant differences were observed, although they were close to the set level of significance $(p=0.074)$. No statistically significant differences was found either between incontinence occurrence after labor and education level or the occurrence of chronic diseases in the studied group ( $p>0.05$ ).

Incontinence occurrence after labor was significantly dependent on the number of experienced labors $(p=0.044)$ as well as with the damage to the perineum $(p=0.025)$. Obtained data indicate that one in four women that had given birth to two or three children complained of symptoms of incontinence, whereas after the first labor, one in ten of the examined women suffered from the involuntary release of urine. The method of delivery and Kegel's exercises proved unimportant ( $p=0.189$ and 0.700 , respectively).
An average infant's body mass in the group was $3412.43 \pm 473.51 \mathrm{~g}$, with the lowest $1990 \mathrm{~g}$ and the highest $4830 \mathrm{~g}$. The dependence between the infant's birth mass and the urinary incontinence has been presented in Table 3 .

In the group of women who experienced incontinence, the average birth mass of an infant was significantly $(p=0.016)$ greater $(3595.09 \pm 581.85)$ than in the case of those without the symptoms $(3376.12 \pm 442.12)$.

The average sex life satisfaction in the studied group was $75.47 \pm 24.68$. This confirmed moderate satisfaction. However, it seems important that among the respondents who obtained the lowest possible score on the SQoL-F scale (0 points) as well as those who achieved the highest score (100 points), the variation of points within the studied group was extensive. Table 4 compiles the data on sex life satisfaction taking into account age, marital status, education, place of habitation, participation in antenatal classes, BMI, presence of chronic diseases, and incontinence occurrence.

The only variable that significantly dependent on sex life satisfaction was urinary incontinence $(p=0.006)$. The differences close to the significant values were noted when the age of the participants was taken into account $(p=0.081)$. In the case of the other variables, no statistically significant differences were found $(p>0.05)$. 


\begin{tabular}{|c|c|c|c|c|c|c|}
\hline \multirow{2}{*}{\multicolumn{3}{|c|}{ Studied characteristics }} & \multicolumn{2}{|l|}{ Incontinence } & \multicolumn{2}{|c|}{ Statistical analysis } \\
\hline & & & $\begin{array}{l}\text { No } \\
n=161 ; 83.4 \%\end{array}$ & $\begin{array}{l}\text { Yes } \\
n=32 ; 16.6 \%\end{array}$ & $x^{2}$ & p-value \\
\hline \multirow{4}{*}{ Labor } & \multirow{2}{*}{$\begin{array}{l}\text { First } \\
n=137 ; 71.0 \%\end{array}$} & $\mathrm{n}$ & 119 & 18 & \multirow{4}{*}{4.04} & \multirow{4}{*}{0.044} \\
\hline & & $\%$ & 86.9 & 13.1 & & \\
\hline & \multirow{2}{*}{$\begin{array}{l}\text { Second or third } \\
n=56 ; 29.0 \%\end{array}$} & $\mathrm{n}$ & 42 & 14 & & \\
\hline & & $\%$ & 75.0 & 25.0 & & \\
\hline \multirow{4}{*}{ Mode of delivery } & \multirow{2}{*}{$\begin{array}{l}\text { Vaginal delivery } \\
n=122 ; 63.2 \%\end{array}$} & $\mathrm{n}$ & 98 & 24 & \multirow{4}{*}{1.73} & \multirow{4}{*}{0.189} \\
\hline & & $\%$ & 80.3 & 19.7 & & \\
\hline & \multirow{2}{*}{$\begin{array}{l}\text { Caesarean section } \\
\mathrm{n}=71 ; 36.8 \%\end{array}$} & $n$ & 63 & 8 & & \\
\hline & & $\%$ & 88.7 & 11.3 & & \\
\hline \multirow{4}{*}{$\begin{array}{l}\text { Perineum damaged } \\
\text { during labor }\end{array}$} & \multirow{2}{*}{$\begin{array}{l}\text { Yes } \\
n=86 ; 44.6 \%\end{array}$} & $\mathrm{n}$ & 66 & 20 & \multirow{4}{*}{4.99} & \multirow{4}{*}{0.025} \\
\hline & & $\%$ & 76.7 & 23.3 & & \\
\hline & \multirow{2}{*}{$\begin{array}{l}\text { No } \\
n=107 ; 55.4 \%\end{array}$} & $\mathrm{n}$ & 95 & 12 & & \\
\hline & & $\%$ & 88.8 & 11.2 & & \\
\hline \multirow{6}{*}{$\begin{array}{l}\text { Exercising pelvic } \\
\text { floor muscles (Kegel's } \\
\text { muscles) }\end{array}$} & \multirow{2}{*}{$\begin{array}{l}\text { Every day } \\
n=61 ; 31.6 \%\end{array}$} & $\mathrm{n}$ & 50 & 11 & \multirow{6}{*}{0.71} & \multirow{6}{*}{0.690} \\
\hline & & $\%$ & 82.0 & 18.0 & & \\
\hline & \multirow{2}{*}{$\begin{array}{l}\text { Does not exercise } \\
n=59 ; 30.6 \%\end{array}$} & $\mathrm{n}$ & 48 & 11 & & \\
\hline & & $\%$ & 81.4 & 18.6 & & \\
\hline & \multirow{2}{*}{$\begin{array}{l}\text { Exercises occasionally } \\
n=73 ; 37.8 \%\end{array}$} & $n$ & 63 & 10 & & \\
\hline & & $\%$ & 86.3 & 13.7 & & \\
\hline
\end{tabular}

\begin{tabular}{|c|c|c|c|c|}
\hline \multirow{2}{*}{\multicolumn{2}{|c|}{$\begin{array}{l}\text { Studied } \\
\text { characteristic }\end{array}$}} & \multirow{3}{*}{$\begin{array}{l}\text { Infant's body mass } \\
M^{*} \pm S D^{* *} \\
3376.12 \pm 442.12\end{array}$} & \multicolumn{2}{|c|}{ Statistical analysis } \\
\hline & & & $\begin{array}{l}\text { t-Student's } \\
t-\text { test }\end{array}$ & p-value \\
\hline \multirow{2}{*}{ 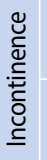 } & $\begin{array}{l}\text { Not present } \\
n=161 ; 83.4 \%\end{array}$ & & \multirow{2}{*}{2.42} & \multirow{2}{*}{0.016} \\
\hline & $\begin{array}{l}\text { Present } \\
\mathrm{n}=32 ; 16.6 \%\end{array}$ & $3595.09 \pm 581.85$ & & \\
\hline \multicolumn{2}{|c|}{ Group total } & $3412.43 \pm 473.51$ & \multicolumn{2}{|l|}{ - } \\
\hline
\end{tabular}

*M - average; **SD - standard deviation

\section{DISCUSSION}

Pregnancy and labor cause numerous changes to a woman's body [11]. These changes might be temporary (functional) or permanent, resulting from alterations within the tissues due to the maximum stretching of the fiber bundles of pelvic floor muscles and perineal nerve fibers in the second stage of labor [12]. A tangible dependence has been observed between vaginal delivery and postpartum incontinence $[13,14]$. Some authors claim that incontinence occurs in $15-30 \%$ of women as early as in the first three months after labor [13]. In our study, incontinence affected $16.6 \%$ of the respondents, but the research was carried out later, i.e. between the third and sixth month after labor. We regret that we did not ask participants when they first noticed symptoms. Nevertheless, the occurrence of incontinence in such a short period after labor can be perceived as a bad prognosis, because in such cases the risk of incontinence development increases greatly [15].

The number of experienced labors proved to be a factor affecting incontinence occurrence after labor $[5,16]$. In our study, one in four women who had given birth to two or more children suffered from incontinence, whereas in the case of the women who had given birth to one child, only one in ten.

Among the women with incontinence after labor, first-time mothers were more numerous than those who had already given birth at least once. During the second part of labor, weakening of the pelvic floor muscles might occur as a result of their tearing or stretching. The resulting changes in pelvic floor muscles do not cause incontinence symptoms straight away. Most commonly directly after birth, so-called subclinical symptoms, which can be diagnosed with the help of ultrasonography, occur, while clinical symptoms become apparent later [17].

Significant differences in the frequency of incontinence were observed $(p=0.025)$ between women with the perineum damaged during labor (episiotomy, rupture, or episiotomy and rupture) and those without any damage. Due to the unsubstantial number of examined patients, we did 
Table 4. Sex life satisfaction and the study characteristics

\begin{tabular}{|c|c|c|c|c|}
\hline \multirow{2}{*}{ Study characteristics } & & \multicolumn{3}{|c|}{ Satisfaction with sex life } \\
\hline & & $M \pm S D$ & $\mathbf{Z}^{*} / \mathbf{H}^{* *}$ & p-values \\
\hline \multirow{3}{*}{ Age } & $\begin{array}{l}\text { Up to } 25 \text { years } \\
n=62 ; 32.1 \%\end{array}$ & $76.52 \pm 24.45$ & \multirow{3}{*}{$5.03^{* *}$} & \multirow{3}{*}{0.081} \\
\hline & $\begin{array}{l}26-30 \text { years } \\
n=75 ; 38.9 \%\end{array}$ & $78.90 \pm 23.09$ & & \\
\hline & $\begin{array}{l}31 \text { years and more } \\
\mathrm{n}=56 ; 29.0 \%\end{array}$ & $69.70 \pm 26.37$ & & \\
\hline \multirow{2}{*}{ Marital status } & $\begin{array}{l}\text { Single } \\
n=40 ; 20.7 \%\end{array}$ & $70.83 \pm 28.02$ & \multirow{2}{*}{$0.95^{*}$} & \multirow{2}{*}{0.354} \\
\hline & $\begin{array}{l}\text { In relationship } \\
\mathrm{n}=153 ; 69.3 \%\end{array}$ & $76.68 \pm 23.68$ & & \\
\hline \multirow{2}{*}{ Education } & $\begin{array}{l}\text { Secondary education or lower } \\
n=53 ; 27.5 \%\end{array}$ & $74.15 \pm 24.60$ & \multirow{2}{*}{$0.29^{*}$} & \multirow{2}{*}{0.771} \\
\hline & $\begin{array}{l}\text { College/University } \\
n=140 ; 72.5 \%\end{array}$ & $75.97 \pm 24.78$ & & \\
\hline \multirow{2}{*}{ Place of habitation } & $\begin{array}{l}\text { City } \\
n=158 ; 81.9 \%\end{array}$ & $76.65 \pm 24.15$ & \multirow{2}{*}{$1.60^{*}$} & \multirow{2}{*}{0.110} \\
\hline & $\begin{array}{l}\text { Country side } \\
\mathrm{n}=35 ; 18.1 \%\end{array}$ & $70.13 \pm 26.67$ & & \\
\hline \multirow{2}{*}{ Participation in antenatal classes } & $\begin{array}{l}\text { Yes } \\
\mathrm{n}=98 ; 50.8 \%\end{array}$ & $72.90 \pm 24.21$ & \multirow{2}{*}{$1.08^{*}$} & \multirow{2}{*}{0.282} \\
\hline & $\begin{array}{l}\text { No } \\
n=95 ; 49.2 \%\end{array}$ & $76.54 \pm 24.89$ & & \\
\hline \multirow{3}{*}{ BMI } & $\begin{array}{l}\text { Underweight } \\
\mathrm{n}=17 ; 8.8 \%\end{array}$ & $72.61 \pm 34.43$ & \multirow{3}{*}{$0.41^{* *}$} & \multirow{3}{*}{0.814} \\
\hline & $\begin{array}{l}\text { Normal weight } \\
n=136 ; 70.5 \%\end{array}$ & $75.51 \pm 24.55$ & & \\
\hline & $\begin{array}{l}\text { Overweight } \\
n=40 ; 20.7 \%\end{array}$ & $76.53 \pm 20.55$ & & \\
\hline \multirow{2}{*}{ Suffers from chronic diseases } & $\begin{array}{l}\text { Yes } \\
\mathrm{n}=31 ; 16.1 \%\end{array}$ & $75.18 \pm 25.11$ & \multirow{2}{*}{$0.23^{*}$} & \multirow{2}{*}{0.822} \\
\hline & $\begin{array}{l}\text { No } \\
n=162 ; 83.9 \%\end{array}$ & $76.99 \pm 22.66$ & & \\
\hline \multirow{2}{*}{ Occurrence of incontinence } & $\begin{array}{l}\text { Not present } \\
n=161 ; 83.4 \%\end{array}$ & $77.67 \pm 23.86$ & \multirow{2}{*}{$2.73^{*}$} & \multirow{2}{*}{0.006} \\
\hline & $\begin{array}{l}\text { Present } \\
\mathrm{n}=32 ; 16.6 \%\end{array}$ & $64.38 \pm 26.15$ & & \\
\hline \multicolumn{2}{|l|}{$\begin{array}{l}\text { Group overall } \\
n=193 ; 100.0 \%\end{array}$} & $75.47 \pm 24.68$ & \multicolumn{2}{|l|}{-} \\
\hline
\end{tabular}

*Z - Mann-Whitney U test; **H - Kruskal-Wallis test

not attempt to find differences between women who had an episiotomy and those with rupture. Rockner [18] studied 185 women after labor with episiotomy or spontaneous rupture, and observed the occurrence of incontinence symptoms in $36 \%$ of the studied group. However, there were no significant differences in the occurrence frequency between the groups. This may suggest that perineum damage during labor, irrespective of its underlying cause, increases the risk of incontinence occurrence. This assumption is further confirmed by the fact that routine episiotomy during labor, as incontinence prophylaxis, is controversial amongst vari- ous authors [10,19-22]. Presumptions about the protective effect of surgical labor on urinary incontinence on the basis of the accumulated data have to be attempted very carefully as it is not clear whether urinary incontinence occurred during pregnancy, which ended in Caesarean section due to various causes. The probability of worsening of symptoms after labor in such cases is greater [23].

Mother's body mass and chronic disease occurrence, which are thought to predispose to postnatal incontinence occurrence, proved to be insignificant in the studied group of women $(p>0.05)$. Occupation significantly dependent on 
incontinence occurrence, especially in the case of women performing physical work $(p=0.023)$.

It has been observed in clinical studies that the larger the fetus, the greater the probability of incontinence occurrence after labor [12,24]. Our research has confirmed this. Alling Møller et al. [25] found no such relations.

Pelvic muscle floor dysfunction and the associated incontinence are viewed as the cause of a decrease in sex life satisfaction. [11, 26]. This has been confirmed by our research. Women who did not suffer from this ailment had a significantly higher $(p=0.006)$ score on the Sexual Quality of Life-Female scale (signifying greater satisfaction) than those with this ailment. In the available literature, there were no publications using SQoL-F scale that would describe the influence of muscle fundus dysfunction on the sexual life. Therefore, we searched for the authors' reports that examined this correlation with the use of other tools. Dean et al. assessed women's sexual functions and satisfaction 6 years after labor with the use of Golombok Rust Inventory of Sexual Satisfaction (GRISS). They noted an adverse impact of the urinary incontinence on women's sexual lives [8]. It is worth noting that the variables assumed by these authors [8] (similarly to our research) did not significantly dependent on women's sexual life satisfaction.

Proper contractility of particular pelvic floor muscle bundles during the sexual act causes the narrowing and elongation of the vagina, elevation of the uterus, and makes reaching orgasm easier [27]. Moreover, disordered contractility hinders sexual intercourse, and causes many women who suffer from incontinence to avoid sexual contact in fear of rejection by their partner or dyspareunia [28]. Proper Kegel's muscle exercises during pregnancy and the postpartum period increase deep perineal pouch muscle strength, enabling control of urinary-reproductive system functioning $[11,29]$. Additionally, it is effective in the treatment of stress urinary incontinence (especially minor cases) and improves sex life satisfaction. Hence, Kegel's muscle exercises are recommended for all women in the reproductive period, not only as a free and effective prophylactic measure, but also as an important part of treatment [30].

At present, well-documented knowledge exists concerning the negative impact of vaginal delivery on the functioning of pelvic floor muscles and the urethra. On the basis of the selected bibliography and our own research, it can be concluded that incontinence, as a dysfunction of the deep perineal pouch, has a destructive effect on women's quality of life. Therefore, in the clinical practice, hospital's and primary healthcare medical staff(doctors, physiotherapists, midwives/nurses) should cooperate in the range of prophylactics of this problem. A midwife and a patient should work together to prepare the pelvic floor muscles for labor and delivery. The promotion of Kegel's muscle exercises after labor is crucial.

\section{CONCLUSIONS}

The problem of incontinence after labor affected one in six women. Occupation, number of pregnancies, damage to the perineum during labor, and the infant's birth weight significantly dependent on the incontinence occurrence after labor. The onset of incontinence symptoms in women in the reproductive age has an adverse effect on their sex life satisfaction.

\section{REFERENCES}

1. Fritel $X$, Ringa V, Quiboeuf $E$, et al. Female urinary incontinence, from pregnancy to menopause: a review of epidemiological and pathophysiological findings. Acta Obstet Gynecol Scand. 2012; 91(8): 901-910, doi: 10.1111/j.1600-0412.2012.01419.x, indexed in Pubmed: 22497363.

2. Hunskaar S, Lose $G$, Sykes $D$, et al. The prevalence of urinary incontinence in women in four European countries. BJU Int. 2004; 93(3): 324-330, doi: 10.1111/j.1464-410x.2003.04609.x, indexed in Pubmed: 14764130.

3. Foldspang $\mathrm{A}$, Hvidman $\mathrm{L}, \mathrm{Mommsen} \mathrm{S}$, et al. Postpartum urinary incontinence. Acta Obstet Gynecol Scand. 2003; 82(6): 556-563, doi: 10.1034/j. 1600-0412.2003.00132.x, indexed in Pubmed: 12780427.

4. Ruiz de Viñaspre Hernández R, Rubio Aranda E, Tomás Aznar C. Urinary incontinence and weight changes during pregnancy and post partum: a pending challenge. Midwifery. 2013; 29(12): e123-e129, doi: 10.1016/j. midw.2012.12.004, indexed in Pubmed: 23434034.

5. Tähtinen RM, Cartwright R, Tsui JF, et al. Long-term Impact of Mode of Delivery on Stress Urinary Incontinence and Urgency Urinary Incontinence: A Systematic Review and Meta-analysis. Eur Urol. 2016; 70(1): 148-158, doi: 10.1016/j.eururo.2016.01.037, indexed in Pubmed: 26874810.

6. Mørkved S, Bø K, Schei B, et al. Pelvic floor muscle training during pregnancy to prevent urinary incontinence: a single-blind randomized controlled trial. Obstet Gynecol. 2003; 101(2): 313-319, doi: 10.1016/s00297844(02)02711-4, indexed in Pubmed: 12576255.

7. Steen M. Promoting continence in women following childbirth. Nurs Stand. 2013; 28(1): 49-57, doi: 10.7748/ns2013.09.28.1.49.e7510, indexed in Pubmed: 24003819.

8. Dean N, Wilson D, Herbison $\mathrm{P}$, et al. Sexual function, delivery mode history, pelvic floor muscle exercises and incontinence: a cross-sectional study six years post-partum. Aust N Z J Obstet Gynaecol. 2008; 48(3): 302-311, doi: 10.1111/j.1479-828X.2008.00854.x, indexed in Pubmed: 18532963.

9. Dalpiaz $O$, Kerschbaumer $A$, Mitterberger $M$, et al. Female sexual dysfunction: a new urogynaecological research field. BJU Int. 2008; 101(6): 717-721, doi: 10.1111/j.1464-410X.2007.07442.x, indexed in Pubmed: 18190620.

10. Yang SH, Yang JM, Wang KH, et al. Biologic correlates of sexual function in women with stress urinary incontinence. J Sex Med. 2008; 5(12): 2871-2879, doi: 10.1111/j.1743-6109.2008.00985.x, indexed in Pubmed: 18778309.

11. Jóźwik $M$, Jóźwik $M$, Adamkiewicz $M$, et al. [An updated overview on the anatomy and function of the female pelvic floor, with emphasis on the effect of vaginal delivery]. Med Wieku Rozwoj. 2013; 17(1): 18-30, indexed in Pubmed: 23749692.

12. Jóźwik $M$, Jóźwik M. Partial denervation of the pelvic floor during term vaginal delivery. Int Urogynecol J Pelvic Floor Dysfunct. 2001; 12(2): 81-82, indexed in Pubmed: 11374517.

13. Boyles $\mathrm{SH}, \mathrm{Li} \mathrm{H}, \mathrm{Mori} \mathrm{T}$, et al. Effect of mode of delivery on the incidence of urinary incontinence in primiparous women. Obstet Gynecol. 2009; 113(1): 134-141, doi: 10.1097/AOG.0b013e318191bb37, indexed in Pubmed: 19104369.

14. Thom DH, Rortveit $\mathrm{G}$. Prevalence of postpartum urinary incontinence: a systematic review. Acta Obstet Gynecol Scand. 2010; 89(12): 1511-1522, doi: 10.3109/00016349.2010.526188, indexed in Pubmed: 21050146.

15. MacArthur C, Glazener CMA, Wilson PD, et al. Persistent urinary incontinence and delivery mode history: a six-year longitudinal study. BJOG. 2006; 113(2): 218-224, doi: 10.1111/j.1471-0528.2005.00818.x, indexed in Pubmed: 16412001.

16. Schytt $E$, Lindmark $G$, Waldenström U. Symptoms of stress incontinence 1 year after childbirth: prevalence and predictors in a national Swedish sample. Acta Obstet Gynecol Scand. 2004; 83(10): 928-936, doi: 10.1111/j.0001-6349.2004.00431.x, indexed in Pubmed: 15453888.

17. Falkert $\mathrm{A}$, Endress $\mathrm{E}$, Weigl $\mathrm{M}$, et al. Three-dimensional ultrasound of the pelvic floor 2 days after first delivery: influence of constitutional and 
obstetric factors. Ultrasound Obstet Gynecol. 2010; 35(5): 583-588, doi: 10.1002/uog.7563, indexed in Pubmed: 20084643.

18. Röckner G. Urinary incontinence after perineal trauma at childbirth. Scand J Caring Sci. 1990; 4(4): 169-172, indexed in Pubmed: 2293286.

19. Ducarme G, Pizzoferrato AC, Tayrac R, et al. Perineal prevention and protection in obstetrics: CNGOF clinical practice guidelines. J Gynecol Obstet Hum Reprod. 2018; pii: S2468-7847(18): 30519-1.

20. Williams A, Herron-Marx S, Carolyn $\mathrm{H}$. The prevalence of enduring postnatal perineal morbidity and its relationship to perineal trauma. Midwifery. 2007; 23(4): 392-403, doi: 10.1016/j.midw.2005.12.006, indexed in Pubmed: 17196714.

21. Leeman L, Rogers R, Borders N, et al. The Effect of Perineal Lacerations on Pelvic Floor Function and Anatomy at 6 Months Postpartum in a Prospective Cohort of Nulliparous Women. Birth. 2016; 43(4): 293-302, doi: 10.1111/birt.12258, indexed in Pubmed: 27797099.

22. Živković K, Živković N, Župić T, et al. Effect of Delivery and Episiotomy on the Emergence of Urinary Incontinence in Women: Review of Literature. Acta Clin Croat. 2016; 55(4): 615-624, doi: 10.20471/acc.2016.55.04.12, indexed in Pubmed: 29117653.

23. Rortveit G, Daltveit AK, Hannestad YS, et al. Norwegian EPINCONT Study. Urinary incontinence after vaginal delivery or cesarean section. $\mathrm{N}$ Engl J Med. 2003; 348(10): 900-907, doi: 10.1056/NEJMoa021788, indexed in Pubmed: 12621134
24. Eftekhar T, Hajibaratali B, Ramezanzadeh F, et al. Postpartum evaluation of stress urinary incontinence among primiparas. Int J Gynaecol Obstet. 2006; 94(2): 114-118, doi: 10.1016/j.ijgo.2006.04.042, indexed in Pubmed: 16846603.

25. Alling Møller L, Lose G, Jørgensen T. Risk factors for lower urinary tract symptoms in women 40 to 60 years of age. Obstet Gynecol. 2000; 96(3): 446-451, indexed in Pubmed: 10960640.

26. Leeman LM, Rogers RG. Sex after childbirth: postpartum sexual function. Obstet Gynecol. 2012; 119(3): 647-655, doi: 10.1097/AOG.0b013e3182479611, indexed in Pubmed: 22353966.

27. Shafik A. The role of the levator ani muscle in evacuation, sexual performance and pelvic floor disorders. Int Urogynecol J Pelvic Floor Dysfunct. 2000; 11(6): 361-376, indexed in Pubmed: 11147745.

28. Yeniel AO, Petri E. Pregnancy, childbirth, and sexual function: perceptions and facts. Int Urogynecol J. 2014; 25(1): 5-14, doi: 10.1007/s00192-0132118-7, indexed in Pubmed: 23812577.

29. Whitford HM, Alder B, Jones M. A longitudinal follow up of women in their practice of perinatal pelvic floor exercises and stress urinary incontinence in North-East Scotland. Midwifery. 2007; 23(3): 298-308, doi: 10.1016/j.midw.2006.05.009, indexed in Pubmed: 17049694.

30. Mørkved S, Bø K. Effect of postpartum pelvic floor muscle training in prevention and treatment of urinary incontinence: a one-year follow up. BJOG. 2000; 107(8): 1022-1028, indexed in Pubmed: 10955436. 